in other direc'ions, and could then concentrate its efforts on what is perhaps, after all, its most legitimate and most useful function - that of providing intermediate technical schools on the pattern of the Finsbury School, of which many are required in the metropolis.

The exact terms on which the Government would be prepared to take over this part of your work is a subject on which, of course, I cannot pretend to enter, but a satisfactory basis can, I do not doubt, easily be found.

Your Council would then feel that the great work which they have begun has been handed over in its full vigour to the nation, and that with the nation lies the responsibility of extending and perfecting the system which they have had the honour and the gratification of inaugurating.

I am aware that in making these suggestions, I have raised a somewhat burning question about which there may be difference of opinion, and my apology for this indiscretion, if one is needed, must be the importance of the subject, and the anxiety which we all feel that the technlcal education of our country shall be placed on a firm and enduring national basis.

\section{A FIRST FORESHADOWING OF THE PERIODIC LAW.}

$I^{T}$ is well known that the Newlands-Mendeleeff classification of the elements was preceded by the discoveries of certain numerical relations between the atomic weights of allied elements, due to Döbereiner, Dumas, and others ; but what has been almost entirely ignored is the immense advance made by M. A. E. Béguyer, de Chancourtois, ${ }^{1}$ a French geologist of note, Professor at the École des Mines, who was the first to publish a list of all the known elements in the order of their atomic weights.

M. de Chancourtois embodied his results in two memoirs presented to the French Academy of Sciences in April 1862 and March 1863. These memoirs have never been printed in extenso, ${ }^{2}$ but extracts from them, and additional notes relating to the subject, were published in the Comptes rendus for 1862 (liv. pp. 757,840 , and 967 ; lv. p. 600), I 863 (lvi. pp. 253 and 479), and 1866 (vol. lxiii. p. 24). The first note bears the date of April 7, I862, so that there can be no doubt as to de Chancourtois's claim to priority in this important matter. ${ }^{3}$

I have in my possession a thin quarto pamphlet, by de Chancourtois, entitled "Vis Tellurique : Classement naturel des corps simples ou radicaux, obtenu au moyen d'un système de classification hélicoïdal et numérique " (Paris, Mallet-Bachelier, ${ }^{4}$ 1863), which contains nearly all the extracts from the Comptes rendus, together with some additional matter. It contains, also, what is absolutely essential to the comprehension of de Chancourtois's ideas, the graphic representation of his system, which is not to be found in the Comptes rendus.

I propose to give here a translation of the first communication to the Academy, followed by certain explanatory comments and brief extracts from the other papers :-

"Geological studies in the field of research opened up by M. Elie de Beaumont in his note on volcanic and metalliferous intrusions (émanations) have led me, for the completion of a lithological memoir on which I am now engaged, to a natural classification of the simple bodies and radicles by a table in the form of a helix, founded on the use of numbers which I call characteristic numbers or numerical characteristics.

"My numbers, which are immediately deduced from the measure of the equivalents or other physical or chemical capacities of the different bodies, are, in the main, the proportional numbers given by the treatises on chemistry, these being reduced to half in the case of hydrogen, nitrogen, fluorine, chlorine, bromine,

I Wurtz ("The Atomic Theory," p. I70) and Berthelot ("Les Origines de I'Alchimie," p. 302) give a bare mention of de Chancourtois's name. couples his name with those of Newlands and Strecker, and shows greater appreciation of his work.

appreciation of his work.
M. Friedel, the eminent Profess rr of Organic Chemistry at the Sorbonne, M. Friedel, the eminent Profess or of Organic Chemistry at the Sorbonne,
has kindly procured for me the informati on that the original manuscripts of these memoirs are preserved in the archives of the Institut; I hope to be able to examine them at some future period.

3 IMr. Newlands' first paper, chiefly devoted to showing that the numer.cal differences between the atomic weights of allied elements are approxima:ely multiples of 8 was published on February $7,1866_{3}$ (Chentical Nezus, vol. vii. p. 70); his second paper, in which he arranges the elements in the order of their atomic weights, was published on July $30,186+$ (Chemical Newes, vol. x. ,p. 39) $\mathrm{Ses}$ J. A. R. Newlands "Oa the Discovery of the Periodic Law,"'sc. (Spэn, 1884).

4 Now Gauthier-Villars. iodine, phosphorus, arsenic, lithium, potassium, sodium, and silver; in other words, I either divide the equivalents of these bodies by two in the system in which oxygen is taken as 100, or multiply by two the equivalents of the other bodies in the system in which hydrogen is taken as unity.

"On a cylinder with a circular base, I trace a helix which cuts the generating lines at an angle of $45^{\circ}$. I take the length of one turn of the helix as my unit of length, and starting from a fixed origin, I mark off on the helix lengths corresponding to the different characteristic numbers of the system in which the number for oxygen is taken as unity. The extremities of the lines thus marked off determine points on the cylinder which I call indifferently characteristic points or geometrical characters, and which I distinguish by the ordinary symbols for the different bodies. The same points will evidently be obtained if we take as the unit of length the $\frac{1}{15}$ of a turn of the helix, and mark off on the curve lengths corresponding to the numbers of the system in which hydrogen is represented by unity.

"The series of points thus determined constitutes the graphic representation of my classification, which may easily be traced on a plane surface by supposing the surface of the cylinder developed; by its aid I am enabled to enounce the fundamental theorem of my system: The relations betwcen the properties of different bodies are manifested by simple geometrical relations between the positions of their characteristic points.

"For instance, oxygen, sulphur, selenium, tellurium, bismuth, fall approximately on the same generating line, while magnesium, calcium, iron, strontium, uranium, and barium, fall on the opposite generating line. On either side of the first of these lines we find hydrogen and zinc on the one hand, bromine and iodine, copper and lead on the other; parallel to the second line we find lithium, sodium, potassium, manganese, \&c.

"Simple relations of position on a cylindrical surface would be obviously defined by means of helices, of which the generating lines are only a particular case ; hence, as a complement to the first theorem, we may add the following: Each helix drawn through two characteristic points and passing through several other points or only near them, brings out relations of a certain kind between their properties; likenesses and differences being manifested by a certain numerical order in their succession, for example, immediate sequence or alternation at various periods.

"In order to attain a greater degree of accuracy, it is necessary to discuss the results of different measurements with respect to the same body.

"One question is all-important in this discussion; it is to know if the divergencies which occur may have causes other than the error of experiment. I reply to this question in the affirmative.

"I think that here, as in all determinations of constants which we wish to compare, they must be reduced to the same conditions. This idea seems to me the indispensable complement to the notion of an absolute characteristic number. Once the existence of this absolute number or numerical characteristic guaranteed by the possibility of connecting it afresh with observed facts, certain limits of variation being allowed [literally, varying within certain limits], we promptly arrive at Prout's law, which presents itself as furnishing a means for reducing experimental observations to a comparable state by a series of trials, without this state being even a completely defined one, but, on the contrary, in order to be able to define it. The combination of this principle with the rules for alignment allow me to give the most striking form to my invention. I am thus led to formulate the table of integral numbers, which, as I must not omit to mention, exhibits under certain aspects the résume of the work of M. Dumas on this subject.

"In the construction of this table I have had recourse to the determinations of specific heats, not only as a means of control, but also to find new numbers unattainable by the methods of chemical investigation. By adopting as the constant product of specific ${ }^{3}$ héat by atomic weight, the number which corresponds both to sulphur and to lead, I have deduced from the series of results given by M. Regnault, purely thermic quotients or numbers, which take their places on my alignments in the most felicitous way. I will only quote two examples : firstly, the number 44, obtained from the specific heat of the diamond, which finds its place on the generating line of the characteristic, 12, of carbon, by the side of the characteristic, 43 , which corresponds to one of the equivalents generally accepted for silicon; and another

' This is probably a misprint, as bismuth does not fall on the same generating line in the table. 
characteristic, 36 , of silicon deduced from an equivalent proposed by M. Regnault, and which is very remarkable, from its coincidence with the characteristic of ammonium.

"By the discussion, which has shown me the advisability of accepting various results hitherto looked on as scarcely reconcilable, I have been led to conceive the possibility of reproducing the serics of natural numbers in the series formed by the numerical characteristics of the real or supposed simple bodies supplemented by the characteristics of the compound radicles formed from gazolytic ${ }^{1}$ elements, such as cyanogen, the ammoniums, \&c., and doubtless also by the compound radicles formed from metallic elements, of which the alloys offer us an example. it this natural series, the bodies which are really simple, or at least irreducible by the ordinary means at our disposal, would be represented by the prime numbers. It will be at once seen that there are in my table at least twelve bodies, which, like sodium (23), have characteristics which are prime numbers. This is what led me to perceive this law, which, I believe, is destined, when established, to form one of the bases for the discovery of the law of molecular attraction. The predominance of the law of divisibility by 4 in the series of my table, a predominance which is also to be found in the elements of the theory of numbers, has confirmed me in the idea-an idea in itself really simple - that there is a perfect agreement between bodies, the elements of the material order, and numbers, the elements of the abstract order of things (éléments de la variété matérielle, de la variété abstraite). This goal once caught sight of, it will seem natural that I should have recourse to the theory of numbers to help me attain it. It will seem not less natural that I should also have recourse to higher geometry; for the series of relations it offers cannot fail to afford resources which may enable one to establish connections between the different numerical characteristics.

"My helicoidal system in this way leads me on towards abstract views of an extremely general nature; and on the other hand it should, it seems to me, find an application in the natural ${ }^{2}$ sciences, as a method of classification throughout their whole domain, from the series of simple bodies which forms the prototype, to the opposite extreme of our natural divisions; in it will be found, I believe, the means of bringing into connection simultaneously, and by all their characters, the different terms of those parallel series, orders, families, genera, species, and races, in each natural kingdom, of which men of science have in vain tried to show the affiliation. In geology, as is evident, the application is implicit.

"Whatever may be the import of these considerations, and to return to the principal object of the present memoir, I ihink that the efficacy of the helicoidal system will be admitted as a means towards hastening the advent of the time when chemical phenomena shall be amenable to mathematical investigations.

"My table, by the distribution of bodies in simple or coupled series, by its indication of the existence of conjugate groups, \&c., traces a plan for diverse categories of syntheses and analyses already executed or to be executed ; it draws up very definite programmes for the execution of several researches which are exciting attention. Will not $\mathrm{my}$ series, for instance, essentially chromatic as they are, be a guide in researches on the spectrum? Will not the relations of the different rays of the spectrum prove to be derived directly from the law of numerical characteristics, or vice versa? This idea, which occurred to me before we were taught the identification of the lines in the spectrum, and the admirable applications of this discovery, seems to me now even more than probable. Finally, looking upon it only as a concise representation of known facts, and reducing it to the points which offer no matter for discussion, the geometrical table of numerical characteristics affords a rapid method for teaching a large number of notions in physics, chemistry, mineralogy, and geology. I hope, therefore, that my natural classification of the simple bodies and radicles being capable of rendering manifold services, will need, like every object in habitual use, a name of easy application; hence, on account of its graphic representation and its origin, I give it the significant name of telluric helix."

It will be well to point out immediately that M. de Chancourtois's system assigns to the numerical characteristics of the elements a general formula of the form $\left(n+16 n^{\prime}\right)$, where $n^{\prime}$ is necessarily an integer $;^{3}$ and his table thus brings out the fact

r Metalloid.

The term includes physical science.

$3 n$ is always represented in the author's table as integral, but he expressly states that he looks on this as by no means necessary. "The construction of the telluric helix rests on the use of proportional numbers derived from that the differences between the atomic weights of allied bodies approximate in many cases to multiples of 16 .

Thus we get the parallel series of which our author speaks-

$$
\begin{aligned}
& \begin{array}{c}
\mathrm{Li} \\
7
\end{array} \ldots \quad 7+\mathrm{I}^{\mathrm{Na}}=23 \quad \ldots \quad 7+2 \cdot \mathrm{K} 6=39 \quad \ldots \quad 7+3 \cdot \mathrm{Mn} 6=55 \\
& \mathrm{Rb} \\
& 7+5 \cdot 16=87 .^{2} \\
& \mathrm{Se} \quad \mathrm{Te}
\end{aligned}
$$

As we glance at the first two turns of de Chancourtois's helix. we ask ourselves if the discovery of Newlands and :Mendeleeff does not lie before us.

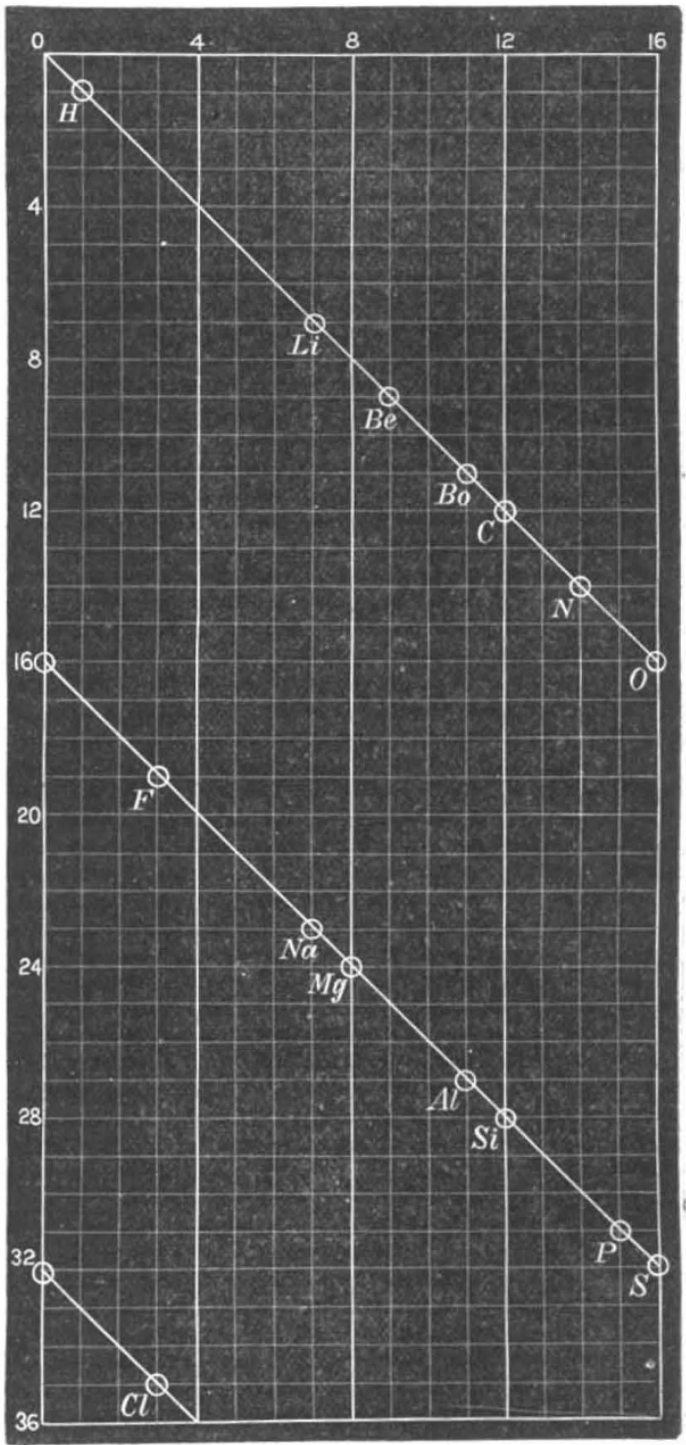

But the discovery of the "octaves" or "periods" cannot be ascribed to our author, although it seems almost impossible that chemists should not have perceived their existence on looking at his table.

experiment. It would remain valid with fractional numbers, and often the hel.coidal alignments would be even more easily applicable to these than to integers" (Comptes rendus, vol. liv. p. 842)

This fact, now familiar, has again been noticed by your correspondent, $\mathrm{Mr}$. A. M. Stapley, in the issue of November 21,1889 .

The atomic weigbt of rubidium should be 85 . We may notice that the author gives as probable also $\mathrm{Cs}=135=7+8.16$, which is thus placed on the same generating line.

3 Certainly too high a value; according to Brauner, the exact atomic weight of tellurium remains to be determined. 
Three important points, however, do exist in common between de Chancourtois's system and that of Mendeleeff :-

Firstly, all the known elements are arranged in the order of their combining weights.

Secondly, the combining weights chosen as best suited to bring out clearly the numerical relations existing between them are those adopted by Cannizzaro in 1858 , a striking fact when we recollect that de Chancourtois wrote only in $\mathbf{1} 862$, at a date long before these numbers had gained anything like general acceptance.

Lastly, an attempt is made to show that simple numerical relations exist, not only between the combining weights, but between all the measurable properties (toutes les capacités physiques et chimiques) of allied elements.

The reasons for the neglect of de Chancourtois's researches and the oblivion into which they have fallen are not far to seek. His style was heavy and at times obscure, and, moreover, his ideas were presented in a way most unattractive to chemists.

A geologist by profession, de Chancourtois had been powerfully impressed by the facts of isomorphism in the case of the feldspars and pyroxenes, which form such important constituents of the volcanic rocks he was studying; and he was thus led to seek for a system of classification which should bring out some simple relationship between the elements they contained.

To quote from his paper (Comptes rendus, vol. liv. p. 969) : "The parallelism of the groups of manganese $(7+3 \cdot 16)$ and iron $(8+3,16)$, of potassium $(7+2,16)$ and calcium $(8+2,16)$, of sodium $(7+16)$ and magnesium $(8+16)$, is the origin of my system "; and again, suggesting the expediency of adopting $55(=7+3 \cdot 16)$ as a characteristic for aluminium, which would bring the element on the sodium and potassium generating line, "this would render perfect the parallelism between the elements of the feldspars and the pyroxenes, the starting-point of my system "(Comptes rendus, lvi. p. 1479).

Thus the correct idea of seeking for a relationship between the combining weights of isomorphous elements was marred by a somewhat imperfect comprehension of the facts of isomorphism. No chemist would certainly have tried to show any close relationship between aluminium on the one hand and the group of the alkalies on the other, notwithstanding their union in the feldspars and pyroxenes; and a suggestion of this kind served to cast discredit on de Chancourtois's really important views.

Notwithstanding his frequently eccentric ideas, de Chancourtois had the merit, so rare in an inventor of this stamp, of not considering his system as final. We cannot do better than let him speak for himself; and quote the conclusion of his last paper on the subject (Comptes rendus, lvi. p. 48I) :- "In presence of the rapid increase in the list of elements which engage the attention of chemists and physicists, it has become urgent to unite in one synthesis all the notions of chemical and physical capacities, of which the exposition would otherwise become an impossible task.

"It is, therefore, perhaps not unnecessary to recall the ideas of Pythagoras, or what I may better term the Biblical truth which dominates all the sciences, and of which I propose to make practical use by the following concrete example, ${ }^{1}$ the first general conclusion of my essay :-

"THE PROPERTIES OF BODIES ARE THE PROPERTIES OF NUMBERS.

"It is easily perceived, that a helicoidal system of some kind or another, which is necessarily a graphic table of divisibility, offers the most convenient means for rendering manifest the relations between the two orders of ideas. It is evident, also, that the particular system which I have adopted brings into relief the relations of the most important and usual of the properties of matter, because the case of divisibility by 4 , which is the basis of my plan, is the first which presents itself in arithmetical speculation after the case of divisibility by 2 , to which ther corresponds directly, as one perceives by a first glance at my table, the existence of the natural couples of elements, with consecutive odd and even characteristics.

"I hope, therefore, that the telluric helix will offer, until it is replaced by some more perfect invention, a practical framework, a convenient scale, on which to set down and compare all measurements of capacities, whatever the point of view which may be taken, whatever elasticity or variation, whatever interpretation may be given to the numerical characteristics, by which these capacities must always be represented.

\footnotetext{
${ }^{2}$ The French is aulgarisation, literally popularization.
}

"The development in a plane of the cylinder ruled into squares, with the circumference at the base divided into I6 equal parts, seems to me, in a word, to be a stave on which men of science, after the fashion of musicians, will note down the results of their experimental or speculative studies, either to co-ordinate their work, or to give a summary of it in the most concise and clear form to their colleagues and the public."

Lothar Meyer has noted down his classification in the form of a helix, ${ }^{1}$ and Dr. Johnstone Stoney, F.R.S., has shown that the numerical values of the atomic weights may be expressed geometrically as functions of a series of integral numbers by points all lying approximately on a logarithmic spiral.

But no simple mathematical formula has so far been discovered to express the relationships of the atomic weights accuratelyi.e. within the limits of experimental error, and de Chancourtois's predictions still remain but incompletely fulfilled.

I need not comment further on the remarkable breadth and originality of our author's views, taken as a whole. Strange to say, it was only a year or two before his death that he heard, through a colleague, of the immense development they had undergone; nor did he ever set up any claims to priority. But when we speak of the greatest generalization of modern chemistry, and recall the names of Newlands and Mendeleeff, it is only just that we should no longer forget their distinguished precursor, de Chancourtois.

P. J. HARTOG.

\section{SCIENTIFIC SERIALS.}

American Journal of Science, December.-The temperature of the moon, by S. P. Langley, with the assistance of F. W. Bery. With this memoir the authors complete the researches begun at the Allegheny Observatory in 1883 and continued during the next four years. The main outcome is that the mean temperature of the sunlit lunar surface is much lower than has been supposed, most probably not being greatly above $0^{\circ}$ C. - The Lower Cretaceous of the South-West, and its relation to the underlying and overlying formations, by Charles A. White. The chalk formations constituting the so-called "Texas Section" are here referred to two natural divisions, which may be designated the Upper and Lower Cretaceous respectively, although not necessarily the exact equivalents of the corresponding European strata. Their fossil contents show that each represents an unbroken portion of Cretaceous time, while the palæontological contrast between the two indicates that there is a time hiatus between them. But this hiatus is no greater than exhibited in others of the mountain uplifts in the same region, and not so great as it is in some cases.-On the hinge of Pelecypods and its development, with an attempt toward a better subdivision of the group, by William H. Dall. Three fundamental types of hinges are described, and on these is based a new classification comprising the three orders of Anomalodesmacea with five sub-orders, Prionodesmacea with eight sub-orders, and Teleodesmacea with eleven or more suborders. - The magnetism of nickel and tungsten alloys, by John Trowbridge and Samuel Sheldon. The question is here discussed whether nickel and tungsten alloys magnetized to saturation increase in specific magnetism as different kinds of steel alloyed in small proportions with tungsten or wolfram are known to do. The tabulated results show that tungsten greatly increases the magnetic moment of nickel, if the alloy be forged and rolled, but has small influence if simply cast ; nor do changes in the amount of tungsten appear to cause corresponding changes in the magnetic properties of the alloy.-Note on the measurement of the internal resistance of batteries, by B. O. Peirce and R. W. Willson. The authors' researches show that the value of the resistance of a cell obtained by the use of alternate currents is always smaller than that obtained by other methods, but the application of the method of alternate currents " fatigues" all but the so-called constant cells. In most cases there is a tendency in the internal resistance to decrease as the strength of the current which the cell is delivering increases.-Papers were contributed by Robert T. Hill and R. A. F. Penrose, Jun., on the relation of the uppermost Cretaceous beds of the Eastern and Southern United States, and on the Tertiary Cretaceous parting of Arkansas and Texas; by W. E. Hidden and

x "Die modernen Theorien der Chemie," iv. Auflage, p. 137; English translation, p. ir8. 